\title{
CSF Levels of CXCL12 and Osteopontin as Early Markers of Primary Progressive Multiple Sclerosis
}

\author{
Damiano Marastoni, MD, * Roberta Magliozzi, PhD,* Anna Bolzan, MD, Anna Isabella Pisani, PhD, \\ Stefania Rossi, PhD, Francesco Crescenzo, MD, Stefania Montemezzi, MD, Francesca Benedetta Pizzini, PhD, \\ and Massimiliano Calabrese, MD
}

Neurol Neuroimmunol Neuroinflamm 2021;8:e1083. doi:10.1212/NXI.0000000000001083

\section{Abstract}

\section{Background and Objectives}

To evaluate the extent of intrathecal inflammation in patients with primary progressive MS (PPMS) at the time of diagnosis and to define markers and a specific inflammatory profile capable of distinguishing progressive from relapsing-remitting multiple sclerosis (RRMS).

\section{Methods}

Levels of 34 pro- and anti-inflammatory cytokines and chemokines in the CSF were evaluated at the diagnosis in 16 patients with PPMS and 80 with RRMS. All patients underwent clinical evaluation, including Expanded Disability Status Scale assessment and a 3T brain MRI to detect white matter and cortical lesion number and volume and global and regional cortical thickness.

\section{Results}

Higher levels of CXCL12 (odds ratio $[\mathrm{OR}]=3.97,95 \%$ CI $[1.34-11.7]$ ) and the monocyterelated osteopontin ( $\mathrm{OR}=2.24,95 \% \mathrm{CI}[1.01-4.99])$ were detected in patients with PPMS, whereas levels of interleukin-10 (IL10) (OR $=0.28,95 \%$ CI [0.09-0.96]) were significantly increased in those with RRMS. High CXCL12 levels were detected in patients with increased gray matter lesion number and volume $(p=0.001, \mathrm{r}=0.832$ and $\mathrm{r}=0.821$, respectively). Pathway analysis confirmed the chronic inflammatory processes occurring in PPMS.

\section{Conclusions}

At the time of diagnosis, a specific CSF protein profile can recognize the presence of early intrathecal inflammatory processes, possibly stratifying PPMS with respect to RRMS. Elevated CSF levels of CXCL12 and osteopontin suggested a key role of brain innate immunity and glia activity in MS. These molecules could represent useful candidate markers of MS progression, with implications for the pathogenesis and treatment of progressive MS.

\section{Classification of Evidence}

This study provides Class III evidence that CXCL12 and monocyte-related osteopontin may be correlated with PPMS, and IL-10 may be related to RRMS. It is may be correlated due to Bonferroni correction negating the statistical correlations found in the study.

\author{
Correspondence \\ Dr. Calabrese \\ massimiliano.calabrese@univr.it
}

\section{(III) Class of Evidence \\ Criteria for rating \\ therapeutic and diagnostic \\ studies \\ NPub.org/coe}




\section{Glossary}

BAFF = B-cell activating factor; $\mathbf{C C L}=$ chemokine $(\mathrm{C}-\mathrm{C}$ motif) ligand; $\mathrm{CTh}=$ cortical thickness; $\mathbf{C X C L}=$ chemokine $(\mathrm{C}-\mathrm{X}-\mathrm{C}$ motif) ligand; DIR = double inversion recovery; EDSS = Expanded Disability Status Scale; IgG = immunoglobulin G; IL = interleukin; MIPAV = Medical Image Processing and Visualization; MMP = matrix metallopeptidase; $\mathbf{M S}=$ multiple sclerosis; OR = odds ratio; PPMS = primary progressive MS; RRMS = relapsing-remitting MS; SPMS = secondary progressive MS; sTNFR = soluble TNF receptor; TE = echo time; TI = inversion time; TNF = tumor necrosis factor; TR $=$ repetition time; TSE = turbo spin echo; TWEAK = TNF-related weak inducer of apoptosis; VIF = variance inflation factor; $\mathbf{W M}=$ white matter; WMLV = WM lesion volume.

Multiple sclerosis (MS) is the most common immunemediated disorder of the CNS. The disease course is usually characterized by an initial relapsing-remitting MS (RRMS) phase, defined by the occurrence of new neurologic symptoms and subsequent disability. Later in the disease course, most patients enter a secondary progressive MS (SPMS) phase defined by progressive accumulation of disability, mostly independent of relapses. ${ }^{1,2}$ About $10 \%-15 \%$ of patients exhibit a progressive disease course from the onset (primary progressive MS [PPMS]), with superimposed relapses in few cases. ${ }^{3}$

Both focal and diffuse white matter (WM) and gray matter (GM) damage characterize MS pathology. ${ }^{4,5}$ GM damage occurs since earlier disease stages ${ }^{5,6}$ and is a negative prognostic factor for MS-related disability. ${ }^{7}$ Inflammation is a major driving force in progressive MS: inflammatory infiltrates, particularly compartmentalized in the meningeal spaces, persist in both SPMS and PPMS associating with GM subpial demyelination and a severe disease course. ${ }^{8-11}$ In a combined ex vivo and in vivo study, CSF analysis revealed an inflammatory profile that associates with GM pathology ${ }^{12}$ and predicts MS disease activity in the first years after diagnosis. ${ }^{13}$ Here, we evaluated the presence and levels of inflammatory markers in the CSF of patients with PPMS at the time of diagnosis, with the aim to identify molecules capable of distinguishing PPMS from RRMS. This will shed some light on the pathogenesis of progressive MS and, at the same time, will define in vivo the extent of intrathecal inflammation in PPMS and its association with disease severity.

\section{Methods}

\section{Patient Cohort}

Sixteen consecutive treatment-naive patients with PPMS and 80 with RRMS from the MS Center of Verona University Hospital (Italy) were evaluated at diagnosis between September 2014 and February 2017. Age and disability were different between the 2 groups, whereas the disease duration was similar. Detailed demographic, clinical, and MRI characteristics of patients with MS are shown in Table 1. All patients had a confirmed MS diagnosis according to the most recent diagnostic criteria. ${ }^{14}$ They underwent a neurologic evaluation, including the Expanded Disability Status Scale (EDSS) assessment, ${ }^{15}$ a brain 3T MRI, and CSF examination. A group of 13 age- and sex-matched (with patients with PPMS) controls with noninflammatory neurologic disorders (2 myopathy, 2 ischemic stroke, 2 peripheral neuropathy, 1 idiopathic tremor, 1 migraine, 1 fibromyalgia, 1 spondylotic myelopathy, 1 amyotrophic lateral sclerosis, 1 idiopathic spastic paraparesis, and 1 endocranial hypertension) that underwent neurologic evaluation and lumbar puncture was also included in the study.

\section{Standard Protocol Approvals, Registrations, and Patient Consents}

The local ethics committee of the University of Verona approved the study, and all the patients signed an informed consent.

\section{CSF Analysis}

CSF samples were obtained at least 1 month after the last relapse and within 1 week of the MRI, according to the Consensus Guidelines for CSF and Blood Biobanking. ${ }^{16}$ After centrifugation, the supernatant and the cell pellet were stored separately at $-80^{\circ} \mathrm{C}$ until use. Immunoglobulin $\mathrm{G}$ index and presence/absence of oligoclonal bands for each patient with MS were evaluated. Analysis of CSF levels of 34 inflammatory mediators was performed using a combination of immune assay multiplex techniques based on the Luminex technology (37and 40-plex customized panel, Bio-Plex X200 System equipped with a magnetic workstation; BioRad, Hercules, CA) using BioPlex Software Manager 6.1 as previously described. ${ }^{12}$ All samples were analyzed in duplicate in 2 independent experiments to verify the results' reproducibility and consistency. The CSF level of each protein detected during the analysis was normalized to the total protein concentration of each CSF sample (measured by the Bradford protocol). ${ }^{12}$

\section{MRI Protocol and Analysis}

Three-Tesla MRI equipped with a 8-channel head coil was performed at the Radiology Unit of the University Hospital of Verona using a Philips Achieva 3T MRI Scanner, on each patient at least 1 month from the last relapse. MRI sequences were acquired as previously described. ${ }^{12}$ The following sequences were acquired: (a) 3D T1-weighted turbo field echo (repetition time (TR)/echo time $(\mathrm{TE})=8.4 / 3.7 \mathrm{~ms}$, voxel size of $1 \times 1 \times 1 \mathrm{~mm}$ ), total acquisition time of 5:51 minutes; (b) 3D double inversion recovery $(\mathrm{DIR})(\mathrm{TR} / \mathrm{TE}=5,500 / 292 \mathrm{~ms}$, inversion times $(\mathrm{TI})$ $\mathrm{TI} 1 / \mathrm{TI} 2=525 \mathrm{~ms} / 2530 \mathrm{~ms}$ voxel size of $1 \times 1 \times 1 \mathrm{~mm}$ ), turbo spin echo (TSE) readout with an optimal variable flip angle scheme, number of excitations 3 , the total acquisition time of 10 : 49 minutes; and (c) 3D fluid attenuated inversion recovery $($ FLAIR $)(T R / T E=5,500 / 292 \mathrm{~ms}, \mathrm{TI}=1650 \mathrm{~ms}$ voxel size of 1 
Table 1 Demographic, Clinical, and MRI Characteristics of Patients With MS

\begin{tabular}{|c|c|c|c|c|}
\hline & Total MS & PPMS & RRMS & $p$ Value \\
\hline $\mathbf{N}$ & 96 & 16 & 80 & \\
\hline Age (y); mean \pm SD; median (IQR) & $\begin{array}{l}39.7 \pm 13.2 \\
38.5(29-49)\end{array}$ & $\begin{array}{l}54.2 \pm 9.4 \\
55.5(49.5-60.8)\end{array}$ & $\begin{array}{l}36.8 \pm 11.9 \\
35(26.3-45.8)\end{array}$ & $<0.001^{\mathrm{a}}$ \\
\hline Sex (F:M) & $68: 28$ & $6: 10$ & $62: 18$ & $0.080^{\mathrm{b}}$ \\
\hline Disease duration $(y)$; mean $\pm S D$; median (IQR) & $\begin{array}{l}6.2 \pm 5.3 \\
5(3-8)\end{array}$ & $\begin{array}{l}6.2 \pm 8.5 \\
4(1-5)\end{array}$ & $\begin{array}{l}6.2 \pm 4.4 \\
5(3-8)\end{array}$ & $0.160^{\mathrm{a}}$ \\
\hline Median EDSS score (IQR) & $2(1-3)$ & $3.5(3-4)$ & $2(1-2.375)$ & $<0.001^{a}$ \\
\hline OCB (positive/negative/n.a.) & 78/17/1 & $11 / 4 / 1$ & $67 / 13$ & $0.500^{b}$ \\
\hline IgG index; mean $\pm S D$; median (IQR) & $\begin{array}{l}0.8 \pm 0.4 \\
0.7(0.6-0.9)\end{array}$ & $\begin{array}{l}0.7 \pm 0.2 \\
0.61(0.5-0.8)\end{array}$ & $\begin{array}{l}0.8 \pm 0.4 \\
0.7(0.6-1)\end{array}$ & $0.200^{\mathrm{a}}$ \\
\hline WMLN; mean \pm SD; median (IQR) & $\begin{array}{l}8.9 \pm 4.1 \\
8(6-12)\end{array}$ & $\begin{array}{l}10.1 \pm 5.4 \\
13(4-15)\end{array}$ & $\begin{array}{l}8.6 \pm 3.8 \\
8(6-11)\end{array}$ & $0.400^{a}$ \\
\hline WMLV $\left(\mathrm{mm}^{3}\right)$; mean $\pm \mathrm{SD}$; median $(\mathrm{IQR})$ & $\begin{array}{l}1,167.9 \pm 1,268.8 \\
857(470-1,331)\end{array}$ & $\begin{array}{l}2,738.7 \pm 2,404.8 \\
1,590(779-5,050)\end{array}$ & $\begin{array}{l}853.8 \pm 487.9 \\
787(459-1,024)\end{array}$ & $0.007^{a}$ \\
\hline CLN; mean \pm SD; median (IQR) & $\begin{array}{l}4.3 \pm 5.2 \\
2.5(0-7.8)\end{array}$ & $\begin{array}{l}5.7 \pm 5.5 \\
3.5(0.3-10.8)\end{array}$ & $\begin{array}{l}4.1 \pm 5.1 \\
2(0-7)\end{array}$ & $0.200^{a}$ \\
\hline $\mathrm{CLV}\left(\mathrm{mm}^{3}\right)$; mean $\pm \mathrm{SD} ;$ median $(\mathrm{IQR})$ & $\begin{array}{l}431.4 \pm 561.5 \\
222(0-694)\end{array}$ & $\begin{array}{l}646.7 \pm 688.8 \\
505(26.3-1,136)\end{array}$ & $\begin{array}{l}387.3 \pm 526.1 \\
188(0-647)\end{array}$ & $0.200^{a}$ \\
\hline CTh $(\mathrm{mm}) ;$ mean $\pm \mathrm{SD}$; median (IQR) & $\begin{array}{l}2.5 \pm 0.4 \\
2.5(2.2-2.7)\end{array}$ & $\begin{array}{l}2.4 \pm 0.5 \\
2.3(2.1-3)\end{array}$ & $\begin{array}{l}2.5 \pm 0.3 \\
2.5(2.2-2-7)\end{array}$ & $0.500^{a}$ \\
\hline
\end{tabular}

Abbreviations: $C L N=$ cortical lesion number; $C L V=$ cortical lesion volume; $C T h=$ global cortical thickness; EDSS = Expanded Disability Status Scale; IgG index, = immunoglobulin G index; IQR = interquartile range; OCB = oligoclonal band; RRMS = relapsing-remitting MS; WMLN = T2 white matter lesion number; WMLV = T2 white matter lesion volume.

$p$ Values after adjustment for multiple comparisons are reported.

a Mann-Whitney test.

${ }^{\mathrm{b}}$ Fisher exact test.

$\times 1 \times 1 \mathrm{~mm}$ ), same TSE readout as the DIR sequence, number of excitations 1 , the total acquisition time of 5:44 minutes

\section{WM Lesion Detection and Lesion Load Assessment}

To identify and segment WM lesions, thus obtaining a T2 hyperintense WM lesion volume (WMLV) at baseline, a semiautomatic lesion segmentation technique, included in Medical Image Processing and Visualization (MIPAV, mipav. cit.nih.gov) software, was applied to FLAIR images.

\section{Cortical Lesion Number and Volume}

The number of cortical lesions (CLs) was assessed on DIR images following the recent recommendations for CLs scoring in patients with MS. ${ }^{17}$ Such number included both intracortical and mixed (WM/GM) lesions, whereas subpial were not counted due to technical difficulties. A semiautomatic thresholding technique based on a Fuzzy C-mean algorithm ${ }^{18}$ included in MIPAV software was adopted to calculate the total $\mathrm{CL}$ volume.

\section{Cortical Thickness Evaluation}

FreeSurfer (release v5.3.0), semiautomatic software based on a T1weighted structural volumetric image (surfer.nmr.mgh.harvard. edu/)was adopted to obtain global and regional measurements of the cortical thickness $(\mathrm{CTh})$ and a semiautomatic procedure with lesion filling, was used to correct topological defects in the cortical surface due to intracortical lesions. Regions included in the correlation analysis were cingulate, cuneus, insula, precentral gyrus, precuneus, superior frontal gyrus, and hippocampus. The mean of the left and right hemispheres for each region of interest of the FreeSurfer parcellation was considered for the analysis. ${ }^{19}$

\section{Primary Research Question}

Can CSF inflammatory markers distinguish PPMS from RRMS at the time of diagnosis? This study provides Class III evidence that chemokine (C-X-C motif) ligand (CXCL12) and monocyte-related osteopontin may be correlated with PPMS, and interleukin-10 (IL-10) may be related to RRMS. It is may be correlated due to Bonferroni correction negating the statistical correlations found in the study.

\section{Statistical Analysis}

Differences among PP and RR patients' groups were initially assessed with the Mann-Whitney test and Fisher exact test. Inflammatory molecules were divided into subgroups according to their main immunologic function. For each pathway identified, the associations between CSF protein levels at diagnosis and the disease course (PPMS and RRMS) were assessed with logistic regression, adjusted for age at onset. CSF levels were log transformed to obtain reliable odds ratio (OR). The $\log$ base 2 allowed a more intuitive interpretation of ORs, 
Table 2 Levels of the Cytokines and Chemokines Detected in the CSF of Patients With MS

\begin{tabular}{|c|c|c|c|c|}
\hline & Total MS & PPMS & RRMS & PPMS/RRMS \\
\hline \multicolumn{5}{|l|}{ T-cell pathway } \\
\hline IFN gamma & $14.7 \pm 24.0$ & $10.7 \pm 14.1$ & $15.5 \pm 25.6$ & 0.69 \\
\hline IFN alfa2 & $14.2 \pm 18.7$ & $16.2 \pm 15.1$ & $13.8 \pm 19.4$ & 1.18 \\
\hline IFN lambda2 & $191.3 \pm 470.1$ & $259.7 \pm 544.8$ & $177.7 \pm 456.4$ & 1.46 \\
\hline IL12(p40) & $13.1 \pm 21.8$ & $7.4 \pm 13.4$ & $14.2 \pm 23.0$ & 0.52 \\
\hline CXCL8 & $61.7 \pm 79.3$ & $56.3 \pm 69.0$ & $62.8 \pm 81.6$ & 0.90 \\
\hline IL 22 & $33.5 \pm 30.8$ & $32.4 \pm 21.6$ & $33.8 \pm 32.5$ & 0.96 \\
\hline CCL19 & $96.4 \pm 93.2$ & $64.0 \pm 59.2$ & $102.9 \pm 97.6$ & 0.62 \\
\hline CCL20 & $1.0 \pm 1.6$ & $1.0 \pm 1.2$ & $1.0 \pm 1.6$ & 1.02 \\
\hline CCL21 & $1,599.9 \pm 1,000.5$ & $1,300.3 \pm 968.5$ & $1,659.9 \pm 1,001.9$ & 0.78 \\
\hline CCL25 & $123.3 \pm 81.6$ & $141.0 \pm 115.7$ & $119.8 \pm 73.4$ & 1.18 \\
\hline IL4 & $19.9 \pm 18.1$ & $25.4 \pm 19.6$ & $18.7 \pm 17.7$ & 1.35 \\
\hline \multicolumn{5}{|l|}{ B-cell pathway } \\
\hline CXCL12 & $2087.1 \pm 1924.6$ & $2,765.7 \pm 2,173.0$ & $1951.4 \pm 1856.3$ & 1.42 \\
\hline CXCL13 & $11.2 \pm 25.4$ & $5.3 \pm 9.3$ & $12.4 \pm 27.4$ & 0.43 \\
\hline BAFF & $9,894.8 \pm 6,333.8$ & $11,387.0 \pm 10,110.0$ & $9,596.3 \pm 5,319.2$ & 1.19 \\
\hline IL10 & $19.5 \pm 18.6$ & $12.0 \pm 8.8$ & $21.1 \pm 19.6$ & 0.57 \\
\hline IL35 & $286.4 \pm 204.8$ & $270.1 \pm 198.5$ & $289.7 \pm 207.1$ & 0.93 \\
\hline GMCSF & $87.4 \pm 99.8$ & $76.7 \pm 90.0$ & $89.6 \pm 102.0$ & 0.86 \\
\hline \multicolumn{5}{|c|}{ Monocyte/macrophage pathway } \\
\hline IL1beta & $2.5 \pm 3.5$ & $2.0 \pm 2.7$ & $2.5 \pm 3.6$ & 0.80 \\
\hline IL6 & $26.5 \pm 49.2$ & $23.5 \pm 39.0$ & $27.1 \pm 51.1$ & 0.87 \\
\hline CCL2 & $526.2 \pm 598.0$ & $717.4 \pm 674.2$ & $488.0 \pm 578.6$ & 1.47 \\
\hline CCL8 & $183.5 \pm 587.0$ & $157.3 \pm 430.7$ & $188.7 \pm 615.6$ & 0.83 \\
\hline CX3CL1 & $348.4 \pm 248.4$ & $325.6 \pm 260.4$ & $353.0 \pm 247.4$ & 0.92 \\
\hline CXCL10 & $431.6 \pm 507.3$ & $421.4 \pm 425.8$ & $433.6 \pm 524.4$ & 0.97 \\
\hline CXCL11 & $64.6 \pm 499.6$ & $10.6 \pm 26.9$ & $75.4 \pm 547.1$ & 0.14 \\
\hline sCD163 & $49,534.7 \pm 33,284.3$ & $51,226.7 \pm 23,913.1$ & $49,196.3 \pm 34,970.7$ & 1.04 \\
\hline MMP1 & $708.2 \pm 927.3$ & $739.4 \pm 616.9$ & $702.0 \pm 980.6$ & 1.05 \\
\hline MMP2 & $1,165.5 \pm 3,189.4$ & $478.3 \pm 556.0$ & $1,302.9 \pm 3,472.7$ & 0.37 \\
\hline Osteopontin & $84,163.9 \pm 95,433.9$ & $130,158.0 \pm 139,428.3$ & $74,965.1 \pm 82,139.4$ & 1.74 \\
\hline \multicolumn{5}{|l|}{ TNF pathway } \\
\hline TNF & $39.7 \pm 38.4$ & $55.2 \pm 43.1$ & $36.6 \pm 36.9$ & 1.51 \\
\hline STNFR1 & $4,300.7 \pm 2,653.3$ & $5,294.0 \pm 3,304.1$ & $4,102.0 \pm 2,480.6$ & 1.29 \\
\hline STNFR2 & $1,062.4 \pm 886.4$ & $1,604.3 \pm 1,227.6$ & $954.1 \pm 766.4$ & 1.68 \\
\hline APRIL & $54,318.8 \pm 61,277.7$ & $63,853.0 \pm 62,885.8$ & $52,411.9 \pm 61,175.9$ & 1.22 \\
\hline LIGHT & $318.2 \pm 434.0$ & $585.6 \pm 511.1$ & $264.72 \pm 399.5$ & 2.21 \\
\hline Tweak & $2,060.4 \pm 1,979.0$ & $2,337.3 \pm 2,014.9$ & $2,005.0 \pm 1,979.9$ & 1.17 \\
\hline
\end{tabular}

Abbreviations: APRIL = A proliferation-inducing ligand; $\mathrm{CX} 3 \mathrm{CL} 1$ = chemokine (C-X3-C motif) ligand; IFN = interferon; LIGHT = tumor necrosis factor ligand superfamily member 14; PPMS = primary progressive MS; RRMS = relapsing-remitting MS; SCD163 = soluble CD163.

Values are expressed as $\mathrm{pg} / \mathrm{mL}$; mean \pm SD are reported. In the PPMS/RRMS column, values are reported as fold change between the 2 groups. 
Figure 1 Results of ROC Curve Analysis

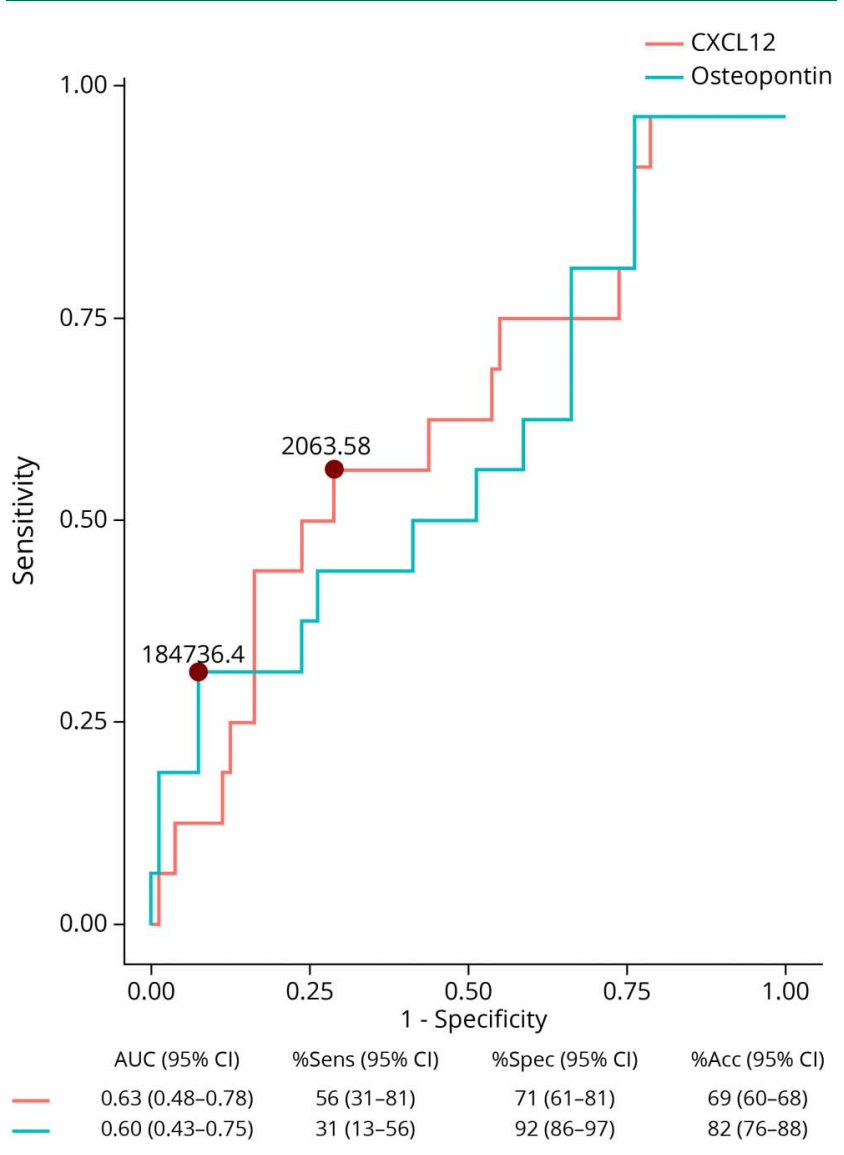

For each protein, AUC, sensitivity, specificity, and accuracy in discriminating between PPMS and RRMS are reported. The optimal threshold for each protein is reported in the curve (red dot) and in the text. Acc = accuracy; AUC $=$ area under the curve; PPMS = primary progressive MS; ROC = receiver operating characteristic; RRMS = relapsing-remitting MS; Sens = sensitivity; Spec $=$ specificity.

as each unit in log base 2 (protein level) corresponds to a doubling in protein level. Before performing the logistic regression models, the multicollinearity among independent variables was checked using the variance inflation factor (VIF). No multicollinearity was detected $(\mathrm{VIF}<10) .^{20}$ The receiver operating characteristic (ROC) analysis (Youden index method) was used to identify both CXCL12 and osteopontin cutoff that maximize specificity and sensitivity of identifying patients with PPMS from RRMS. Sensitivity, specificity, accuracy, and area under curve with 95\% CI were reported. Logistic regression analysis was used to evaluate the association of CXCL12 and Osteopontin levels with a PPMS disease course and noninflammatory controls. A pairwise univariate Spearman rank index was used to evaluate the correlation between EDSS, MRI parameters, and inflammatory molecules in PP patients' group. A false discovery rate correction with significance level of 0.05 was applied. Pathway analysis, including gene ontology analysis, was performed by using Enrichr (maayanlab.cloud/ Enrichr/) analysis. $p$ Value $<0.05$ was considered statistically significant. Statistical analysis was performed with Prism 7.0 and $\mathrm{R}$ studio 3.5 .3 version.

\section{Data Availability}

Deidentified data will be shared on request from a qualified investigator.

\section{Results}

\section{Differences in the CSF Profile Between PPMS and RRMS}

Increased levels of the lymphoid chemokine CXCL12 (fold change 1.42) and of molecules related to monocyte/ macrophage recruitment and innate immunity activity as chemokine (C-C motif) ligand (CCL2) and osteopontin (1.47 and 1.74, respectively) were detected in patients with PPMS compared with RRMS. Patients with PPMS had increased levels of many other cytokines, in particular tumor necrosis factor (TNF) (fold change 1.51), its soluble TNF receptors (sTNFRs) sTNFR1 and sTNFR2 (fold change 1.29 and 1.68, respectively) and the TNF superfamily member TNF ligand superfamily member 14 (fold change 2.21). Among other molecules, levels of IFNlambda and IL4 were increased in patients with PPMS with a fold change of 1.46 and 1.35, respectively. Conversely, patients with RRMS showed higher levels of matrix metallopeptidase (MMP) 2 (fold change 2.72), IL12 (1.91), IL10 (1.73), CCL19 (1.61), CXCL11 (7.1), and CXCL13 (2.34). Levels of all the examined molecules in each MS group are reported in Table 2.

\section{Logistic Regression and ROC Analysis}

The multivariate logistic regression analysis showed that the CSF level at diagnosis of CXCL12 (OR $=3.97,95 \% \mathrm{CI}$ [1.34-11.7]) and osteopontin (OR=2.24, 95\% CI [1.01-4.99]) independently predicted a higher probability of a primary progressive course of the disease. Conversely, elevated IL10 levels were significantly associated with the diagnosis of RRMS (OR = $0.28,95 \%$ CI [0.09-0.96]). ROC curve analysis estimated the optimal cutoff values of 2063.58 and $184,736.4 \mathrm{pg} / \mathrm{mL}$ for CXCL12 and osteopontin, respectively (Figure 1). Both CXCL12 and osteopontin levels were found increased compared with control group patients with noninflammatory neurologic disorders $(\mathrm{OR}=1.10,95 \% \mathrm{CI}[1.05-3.15]$, and $\mathrm{OR}=$ $1.38,95 \%$ CI [1.08-5.23], respectively).

\section{Correlations and Pathway Analysis in PPMS}

Patients with increased CSF CXCL12 showed a concurrent increment of the monocyte chemoattractant protein CCL2 levels ( $\mathrm{r}$ $=0.647, p=0.040$; Figure 2A). Despite a not significant correlation after adjusting for multiple comparisons, the same patients displayed high levels of B-cell activating factor (BAFF) $(r=0.597$, $p=0.064$; Figure $2 \mathrm{~A}), \mathrm{IL} 4(\mathrm{r}=0.653, p=0.106)$, the lymphoid chemokine CCL19 ( $\mathrm{r}=0.603, p=0.129)$, and both the TNF receptors, sTNFR1 $(\mathrm{r}=0.515, p=0.186)$ and sTNFR2 $(\mathrm{r}=0.559$, $p=0.147)$. Pathway analysis revealed these molecules as mainly involved in regulation of dendritic cell (DC) processes, calcium ion import, leukocyte apoptotic processes, immunologic synapse formation, regulation of endothelial cell development and extravasation, and regulation of glial cell apoptotic process (Table 3). 

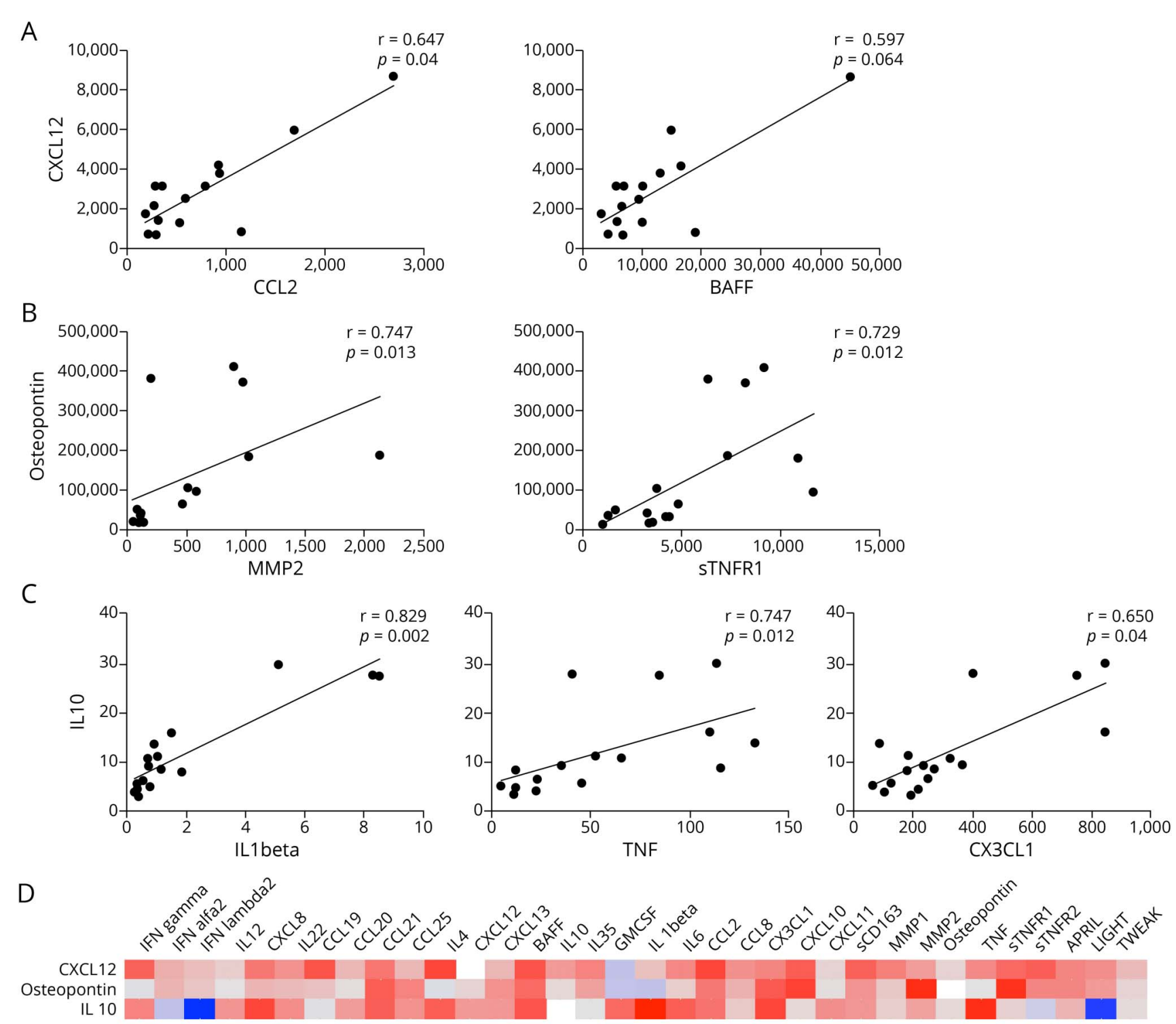

IL 10

$-1$

(A) Correlation analysis of CXCL12 with CCL2 and BAFF levels. (B) Significant correlations between osteopontin and MMP2 and sTNFR1 levels. (C) IL10 levels significantly correlated with IL1beta, TNF, and CX3CL1. (D) Panel showing the entire correlation matrix. CX3CL1 = chemokine (C-X3-C motif) ligand; PPMS = primary progressive MS.

Increased osteopontin levels were detected in PPMS patients with higher expression of MMP2 ( $\mathrm{r}=0.747, p=0.013)$, sTNFR1 ( $\mathrm{r}=0.829, p=0.002$; Figure $2 \mathrm{~B})$, and CXCL10 $(\mathrm{r}=$ $0.674, p=0.040)$, molecules mainly involved in regulation of endothelial cell development and endothelial barrier, regulation of sphingolipid and ceramide biosynthesis, cell death regulation, regulation of cyclic adenosine monophosphate-mediated signaling, regulation of epithelium morphogenesis, and T-cell chemotaxis (Table 3 ).

Finally, patients with high IL10 levels were also characterized by increased TNF $(\mathrm{r}=0.747, p=0.012)$, ILlbeta $(\mathrm{r}$ $=0.829, p=0.002)$, and chemokine ( $\mathrm{C}-\mathrm{X} 3-\mathrm{C}$ motif) ligand $1(\mathrm{r}=0.650, p=0.040)$ CSF levels (Figure 2C). The pathway analysis revealed that these molecules are linked with cell adhesion, regulation of fever generation, regulation of endothelial cell development, cytokine secretion, regulation of membrane protein, response to corticosteroids, and regulation of acute inflammatory response (Table 3). The entire correlation panel is graphically shown in Figure 2D.

\section{Correlations Between CSF Inflammation and Disease Severity in PPMS}

No correlations were found between the selected inflammatory molecules and EDSS (not shown). Both cortical lesion number 
Table 3 Gene Ontology Analysis: Pathways Associated With CXCL12, Osteopontin, IL10, and Their Related Molecules in PPMS

\begin{tabular}{|c|c|c|c|}
\hline Name & $p$ Value & OR & Combined score \\
\hline \multicolumn{4}{|l|}{ CXCL12 and related molecules } \\
\hline (1) Negative regulation of the dendritic cell apoptotic process (G0:2000669) & 0.000001574 & 952.38 & $12,725.67$ \\
\hline (2) Regulation of the dendritic cell apoptotic process (GO:2000668) & 0.000003371 & 666.67 & $8,400.14$ \\
\hline (3) Positive regulation of calcium ion import (GO:0090280) & 0.000003371 & 666.67 & $8,400.14$ \\
\hline (4) Negative regulation of the leukocyte apoptotic process (GO:2000107) & 0.000004943 & 555.56 & $6,787.49$ \\
\hline (5) Positive regulation of dendritic cell antigen processing and presentation (G0:0002606) & 0.001799 & 555.56 & $3,511.45$ \\
\hline (6) Immunologic synapse formation (GO:0001771) & 0.001799 & 555.56 & $3,511.45$ \\
\hline (7) Regulation of endothelial cell development (G0:1901550) & 0.001799 & 555.56 & $3,511.45$ \\
\hline (8) Negative regulation of cellular extravasation (GO:0002692) & 0.001799 & 555.56 & $3,511.45$ \\
\hline (9) Positive regulation of antigen processing and presentation (GO:0002579) & 0.001799 & 555.56 & $3,511.45$ \\
\hline (10) Regulation of the glial cell apoptotic process (GO:0034350) & 0.001799 & 555.56 & $3,511.45$ \\
\hline \multicolumn{4}{|l|}{ Osteopontin and related molecules } \\
\hline (1) Regulation of endothelial cell development (GO:1901550) & 0.001799 & 555.56 & $3,511.45$ \\
\hline (2) Positive regulation of the sphingolipid biosynthetic process (GO:0090154) & 0.002098 & 476.19 & $2,936.47$ \\
\hline (3) Death-inducing signaling complex assembly (GO:0071550) & 0.002098 & 476.19 & $2,936.47$ \\
\hline (4) Positive regulation of the ceramide biosynthetic process (GO:2000304) & 0.002098 & 476.19 & $2,936.47$ \\
\hline (5) Positive regulation of cAMP-mediated signaling (GO:0043950) & 0.002398 & 416.67 & $2,513.82$ \\
\hline (6) Regulation of morphogenesis of an epithelium (GO:1905330) & 0.002697 & 370.37 & $2,190.93$ \\
\hline (7) T-cell chemotaxis (GO:0010818) & 0.002997 & 333.33 & 1936.76 \\
\hline (8) Regulation of T-cell chemotaxis (GO:0010819) & 0.002997 & 333.33 & 1936.76 \\
\hline (9) Regulation of the ceramide biosynthetic process (GO:2000303) & 0.003296 & 303.03 & 1731.85 \\
\hline (10) Regulation of establishment of the endothelial barrier (GO:1903140) & 0.003595 & 277.78 & $1,563.39$ \\
\hline \multicolumn{4}{|l|}{ IL10 and related molecules } \\
\hline (1) Positive regulation of heterotypic cell-cell adhesion (GO:0034116) & $4.948 \mathrm{e}-10$ & $1,363.64$ & $29,218.41$ \\
\hline (2) Positive regulation of fever generation (GO:0031622) & $4.499 \mathrm{e}-7$ & $1,666.67$ & $24,357.23$ \\
\hline (3) Regulation of endothelial cell development (GO:1901550) & $4.499 \mathrm{e}-7$ & $1,666.67$ & $24,357.23$ \\
\hline (4) Positive regulation of cell-cell adhesion (GO:0022409) & $6.138 \mathrm{e}-12$ & 606.06 & $15,646.39$ \\
\hline (5) Regulation of heterotypic cell-cell adhesion (G0:0034114) & $2.905 e-9$ & 789.47 & $15,518.51$ \\
\hline (6) Regulation of cytokine secretion involved in immune response (G0:0002739) & 0.000001079 & $1,111.11$ & $15,265.62$ \\
\hline (7) Regulation of membrane protein ectodomain proteolysis (G0:0051043) & $4.617 \mathrm{e}-9$ & 681.82 & $13,086.55$ \\
\hline (8) Response to corticosteroid (GO:0031960) & 0.000001649 & 909.09 & $12,104.88$ \\
\hline (9) Regulation of establishment of the endothelial barrier (GO:1903140) & 0.000001979 & 833.33 & $10,944.26$ \\
\hline (10) Positive regulation of acute inflammatory response (G0:0002675) & 0.000003147 & 666.67 & $8,446.00$ \\
\hline
\end{tabular}

Abbreviations: OR = odds ratio; PPMS = primary progressive MS; CAMP = cyclic adenosine monophosphate.

$(\mathrm{r}=0.832, p=0.001)$ and cortical lesion volume $(\mathrm{r}=0.821, p=$ $0.001)$ were increased in patients harboring higher intrathecal CXCL12, whereas a similar trend was not observed regarding osteopontin and IL10. No significant associations were observed between CXCL12 and osteopontin levels and WM lesion number or WMLV. CXCL13 levels were particularly 


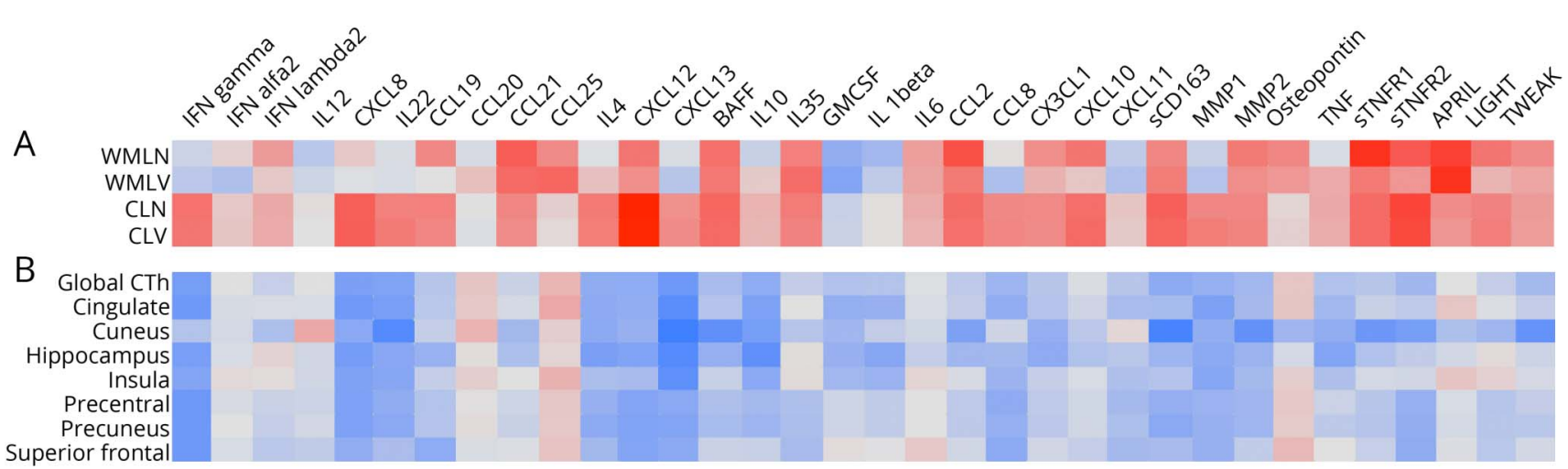

(A) CXCL12 showed a significant correlation with CLN and CLV. (B) CXCL13 best correlated with a reduced global and regional CTh (see text). Among other molecules, sTNFR1 correlated with WMLN $(r=0.741, p=0.014)$. APRIL with WMLV $(r=0.744, p=0.014)$, sTNFR2 with CLN $(r 0.662, p=0.035)$, and CLV $(r=0.646$, $p=0.035)$. $C L N=$ cortical lesion number; $C L V=$ cortical lesion volume; $C T h=$ cortical thickness; PPMS = primary progressive MS; WMLN = white matter lesion number; $\mathrm{WMLV}=$ white matter lesion volume.

increased in those patients with lower CTh of cuneus $(\mathrm{r}=$ $-0.762, p=0.024)$, hippocampus $(\mathrm{r}=-0.678, p=0.063)$, cingulate gyrus $(\mathrm{r}=-0.652, p=0.063)$, and insula $(\mathrm{r}=-0.633$, $p=0.063)$. All correlations are graphically shown in Figure 3.

\section{Discussion}

The analysis of the CSF profile in PPMS revealed that higher CXCL12 and osteopontin are associated with a progressive disease course and suggest that a chronic intrathecal inflammatory process, although partly different from RRMS, also occurs in patients with progressive MS, since the time of diagnosis and independently of relapses.

Such findings are in line with the idea that inflammation exerts a major role in progressive MS, including PPMS. Whether PPMS and RRMS/SPMS represent similar physiopathologic entities has been debated; differences between SPMS and PPMS seem to be quantitative rather than qualitative. ${ }^{8,21}$ Furthermore, the similar age at onset and rates of disability progression indicate that a similar process underlies the 2 entities. ${ }^{22,23}$ Although based on a small cohort, our preliminary results highlighted 2 molecules as associated with the primary progressive disease course: the CXCL12 and the osteopontin.

Besides modulating neuronal activity through multiple regulatory pathways, CXCL12 is a potent chemoattractant molecule for different immune cells, including monocytes, $\mathrm{T}$ cells, $\mathrm{B}$ cells, and plasma cells. ${ }^{24}$ Elevated levels of CXCL12 have been detected both in active and inactive lesions and have been suggested as contributors to the maintenance of immune cells within the CNS. ${ }^{25}$ Along with CXCL13, it mediates germinal center organization in lymphoid tissue, and possibly, a similar process could occur in the CNS of patients with MS, thus contributing to the persistence of B cells and plasma cells in inflamed meninges and perivascular spaces.

In line with previous findings, we have found CXCL12 strictly associated with the local production by astrocytes of the B-cell survival factor $\mathrm{BAFF}^{25}$ and with CLs, thus confirming the link between $\mathrm{B}$ cell-associated CSF inflammation and the adjacent cortical pathology. ${ }^{12,13}$ Probably due to the low sample size, a significant correlation between the CXCL12 and the CTh was not observed. On the contrary, after correction for multiple comparisons, CXCL13 levels correlated with the CTh of many brain regions that are early involved in PPMS pathology. ${ }^{26,27}$ Such observations could have clinical prognostic value, as cortical pathology has been recognized as a crucial substrate for the progression and irreversible clinical and cognitive disability in MS. ${ }^{7,28}$

Osteopontin, which in the brain is mainly released by endothelial cells, microglia, macrophages, and DCs, has a role in mediating MS severity and progression. ${ }^{29-32}$ CSF levels of osteopontin are higher than in plasma, further suggesting a contribution from CNS resident or infiltrating cells as intrathecal sources of the molecule. ${ }^{33}$ It is increased in lesional brain tissue from patients with progressive $\mathrm{MS}^{34}$ and in the CSF of patients with $\mathrm{MS}^{33,35}$ and decreases after treatments. ${ }^{36}$ Of interest, patients with SPMS showed stable and continuously increased osteopontin levels. ${ }^{37}$ Osteopontin mainly reflect activation of innate immune system and exerts an essential role in inflammation and immune response, influencing $\mathrm{T}$ helper differentiation 1-type and 2-type responses, as well as regulating DC migration at multiple levels. ${ }^{38,39}$ Among others, it enhances interferon and IL12 proinflammatory activity and reduces IL10-mediated responses, all cytokines involved in MS and other inflammatory diseases. ${ }^{38}$ 
Osteopontin increases myelin-reactive T-cell survival and induces relapses and progression in experimental autoimmune encephalomyelitis ${ }^{40}$; accordingly, osteopontin-deficient mice show a greater number of remissions, less progression, and higher IL10 levels in a preclinical MS model. ${ }^{34}$ All these shreds of evidence further point to a detrimental role of osteopontin in MS progression since the early stages.

As suggested by pathway analysis, the molecules identified as associated with PPMS in this study are mainly related to several inflammatory processes of both innate and adaptive immune responses that occur in the CNS. Indeed, as MS progresses, inflammation becomes increasingly compartmentalized within the CNS beyond a relatively intact bloodbrain barrier, ${ }^{41-43}$ with lesions showing less prominent focal inflammation but persisting microglia activity at the edge of chronic active demyelinating plaques. ${ }^{44} \mathrm{~A}$ major contribution to MS progression is given by meningeal inflammation: diffuse and clustered meningeal and perivascular infiltrates, enriched in B cells, associated with subpial GM pathology, have been detected in both SPMS and PPMS postmortem brains, although, in the case of PPMS, they appeared less extensive and not clustered in tertiary lymphoid follicles. ${ }^{9-11,42}$

The current study is mainly limited by the low number of PPMS cases evaluated, whose follow-up is still ongoing. This implies that our observations are preliminary and that further validation in a larger cohort is needed. The analysis of CSF intrathecal profile in a larger cohort could confirm the markers capability to early identify patients with severe progressive MS course that could benefit from an immunosuppressant approach.

In summary, our work showed that (1) intrathecal inflammation is significant in the CSF of patients with PPMS at the time of diagnosis; (2) the CSF profile of patients with PPMS is characterized explicitly by higher levels of CXCL12 and osteopontin when compared with patients with RRMS and associate with a specific proinflammatory innate immune profile; (3) as observed in RRMS, also in PPMS, the lymphoid chemokines CXCL12 and CXCL13 are associated with an increased level of GM pathology already at the time of diagnosis. Our observations highlight the potential differential signature of intrathecal inflammation in PPMS, suggesting possible clinical implications for the diagnosis and treatment of PPMS that warrant further investigations.

\section{Study Funding}

Dr. Magliozzi was supported by grant from the Italian MS Foundation (FISM 16/17/F14). Prof. Calabrese was supported by the GR-2013-02-355,322 grant from Italian Ministry of Health. Prof. Calabrese was supported by the GR-2013-02355322 grant from Italian Ministry of Health.

\section{Disclosure}

The authors report no disclosures relevant to this manuscript. Go to Neurology.org/NN for full disclosures.

\section{Publication History}

Received by Neurology: Neuroimmunology \& Neuroinflammation March 1, 2021. Accepted in final form July 21, 2021.

Appendix Authors

\begin{tabular}{lll}
\hline Name & Location & Contribution \\
\hline $\begin{array}{l}\text { Damiano } \\
\text { Marastoni, MD }\end{array}$ & University of Verona, Italy & $\begin{array}{l}\text { Designed and conceptualized } \\
\text { the study; analyzed and } \\
\text { interpreted the data; and } \\
\text { drafted the manuscript for } \\
\text { intellectual content }\end{array}$ \\
\hline $\begin{array}{ll}\text { Roberta } \\
\text { Magliozzi, PhD }\end{array}$ & $\begin{array}{l}\text { University of Verona, } \\
\text { Italy/Imperial College } \\
\text { London, UK }\end{array}$ & $\begin{array}{l}\text { Designed and conceptualized } \\
\text { the study; analyzed and } \\
\text { interpreted the data; and } \\
\text { drafted the manuscript for } \\
\text { intellectual content }\end{array}$ \\
\hline
\end{tabular}

Anna Bolzan, University of Verona, Italy $\begin{aligned} & \text { Interpreted the data and } \\ & \text { revised the manuscript for } \\ & \text { intellectual content }\end{aligned}$

\begin{tabular}{lll}
\hline $\begin{array}{l}\text { Anna Isabella University of Verona, Italy } \\
\text { Pisani }\end{array}$ & $\begin{array}{l}\text { Analyzed and interpreted the } \\
\text { data and revised the } \\
\text { manuscript for intellectual } \\
\text { content }\end{array}$
\end{tabular}

Stefania Rossi, Higher Institute of Health Acquired and interpreted the

$\begin{array}{ll}\text { PhD Care, Rome } & \text { data and revised the } \\ & \text { manuscript for intellectual } \\ & \text { content }\end{array}$

\begin{tabular}{lll}
\hline $\begin{array}{l}\text { Francesco } \\
\text { Crescenzo, MD }\end{array}$ & University of Verona, Italy & $\begin{array}{l}\text { Interpreted the data and } \\
\text { revised the manuscript for } \\
\text { intellectual content }\end{array}$ \\
\hline $\begin{array}{l}\text { Stefania } \\
\text { Montemezzi, } \\
\text { MD }\end{array}$ & $\begin{array}{l}\text { Integrated University } \\
\text { Hospital of Verona, Italy }\end{array}$ & $\begin{array}{l}\text { Interpreted the data and } \\
\text { revised the manuscript for } \\
\text { intellectual content }\end{array}$ \\
\hline $\begin{array}{l}\text { Francesca } \\
\text { Benedetta } \\
\text { Pizzini, PhD }\end{array}$ & Hospital of Verona, Italy & $\begin{array}{l}\text { Interpreted the data and } \\
\text { revised the manuscript for } \\
\text { intellectual content }\end{array}$ \\
\hline $\begin{array}{l}\text { Massimiliano } \\
\text { Calabrese, MD }\end{array}$ & University of Verona, Italy & $\begin{array}{l}\text { Designed and conceptualized } \\
\text { the study; analyzed and } \\
\text { interpreted the data; and } \\
\text { drafted the manuscript for } \\
\text { intellectual content }\end{array}$ \\
& &
\end{tabular}

\section{References}

1. Thompson AJ, Baranzini SE, Geurts J, Hemmer B, Ciccarelli O. Multiple sclerosis. Lancet. 2018;391(10130):1622-1636.

2. Lublin FD, Reingold SC, Cohen JA, et al. Defining the clinical course of multiple sclerosis: the 2013 revisions. Neurology. 2014;83(3):278-286.

3. Miller DH, Leary SM. Primary-progressive multiple sclerosis. Lancet Neurol. 2007; 6(10):903-912.

4. Kutzelnigg A, Lucchinetti CF, Stadelmann C, et al. Cortical demyelination and diffuse white matter injury in multiple sclerosis. Brain. 2005;128(pt 11):2705-2712.

5. Calabrese M, Magliozzi R, Ciccarelli O, Geurts JJG, Reynolds R, Martin R. Exploring the origins of grey matter damage in multiple sclerosis. Nat Rev Neurosci. 2015;16(3): 147-158.

6. Lucchinetti CF, Popescu BO, Bunyan R, et al. Inflammatory cortical demyelination in early multiple sclerosis. NEJM. 2011;365(23):2188-2197.

7. Calabrese M, Poretto V, Favaretto A, et al. Cortical lesion load associates with progression of disability in multiple sclerosis. Brain. 2012;135(pt 10):2952-2961.

8. Lassmann H. Pathogenic mechanisms associated with different clinical courses of multiple sclerosis. Front Immunol. 2019;9:3116.

9. Magliozzi R, Howell O, Vora A, et al. Meningeal B-cell follicles in secondary progressive multiple sclerosis associate with early onset of disease and severe cortical pathology. Brain. 2007;130(pt 4):1089-1104.

10. Howell OW, Reeves CA, Nicholas R, et al. Meningeal inflammation is widespread and linked to cortical pathology in multiple sclerosis. Brain. 2011;134(pt 9):2755-2771.

11. Choi S, Howell OW, Carassiti D, et al. Meningeal inflammation plays a role in the pathology of primary progressive multiple sclerosis. Brain. 2012;135(pt 10):2925-2937. 
12. Magliozzi R, Howell OW, Nicholas R, et al. Inflammatory intrathecal profiles and cortical damage in multiple sclerosis. Ann Neurol. 2018;83(4):739-755.

13. Magliozzi R, Scalfari A, Pisani AI, et al. The CSF profile linked to cortical damage predicts multiple sclerosis activity. Ann Neurol. 2020;88(3):562-573.

14. Polman CH, Reingold SC, Banwell B, et al. Diagnostic criteria for multiple sclerosis: 2010 revisions to the McDonald criteria. Ann Neurol. 2011;69(2):292-302.

15. Kurtzke JF. Rating neurologic impairment in multiple sclerosis: an expanded disability status scale (EDSS). Neurology. 1983;33(11):1444-1452.

16. Teunissen CE, Petzold A, Bennett JL, et al. A consensus protocol for the standardization of cerebrospinal fluid collection and biobanking. Neurology. 2009;73(22):1914-1922.

17. Geurts JJ, Roosendaal SD, Calabrese M, et al. Consensus recommendations for MS cortical lesion scoring using double inversion recovery MRI. Neurology. 2011;76(5): 418-424.

18. Pham DL, Prince JL. Adaptive fuzzy segmentation of magnetic resonance images. IEEE Trans Med Imaging. 1999;18(9):737-752.

19. Crescenzo F, Marastoni D, Zuco C, et al. Effect of glatiramer acetate on cerebral grey matter pathology in patients with relapsing-remitting multiple sclerosis. Mult Scler Relat Disord. 2019;27:305-311.

20. Vittinghoff E, Glidden DV, Shiboski SC, McCulloch CE. Regression Methods in Biostatistics: Linear, Logistic, Survival, and Repeated Measures Models, 2nd ed. Springer; 2011.

21. Antel J, Antel S, Caramanos Z, Arnold DL, Kuhlmann T. Primary progressive multiple sclerosis: part of the MS disease spectrum or separate disease entity? Acta Neuropathol. 2012;123(5):627-638.

22. Confavreux C, Vukusic S. Age at disability milestones in multiple sclerosis. Brain. 2006;129(pt 3):595-605.

23. Scalfari A, Lederer C, Daumer M, Nicholas R, Ebers GC, Muraro PA. The relationship of age with the clinical phenotype in multiple sclerosis. Mult Scler. 2016;22(13):1750-1758.

24. Guyon A. CXCL12 chemokine and its receptors as major players in the interactions between immune and nervous systems. Front Cel Neurosci. 2014;8:65.

25. Krumbholz M, Theil D, Cepok S, et al. Chemokines in multiple sclerosis: CXCL12 and CXCL13 up-regulation is differentially linked to CNS immune cell recruitment. Brain. 2006;129(pt 1):200-211.

26. Eshaghi A, Bodini B, Ridgway GR, et al. Temporal and spatial evolution of grey matter atrophy in primary progressive multiple sclerosis. Neuroimage. 2014;86:257-264.

27. Eshaghi A, Marinescu RV, Young AL, et al. Progression of regional grey matter atrophy in multiple sclerosis. Brain. 2018;141(6):1665-1677.

28. Fisniku LK, Chard DT, Jackson JS, et al. Gray matter atrophy is related to long-term disability in multiple sclerosis. Ann Neurol. 2008;64(3):247-254.

29. Niino M, Kikuchi S, Fukazawa T, Yabe I, Tashiro K. Genetic polymorphisms of Osteopontin in association with multiple sclerosis in Japanese patients. J Neuroimmunol. 2003;136(1-2):125-129.
30. Chiocchetti A, Comi C, Indelicato $\mathrm{M}$, et al. Osteopontin gene haplotypes correlate with multiple sclerosis development and progression. J Neuroimmunol. 2005;163(12):172-178.

31. Caillier S, Barcellos LF, Baranzini SE, et al. Osteopontin polymorphisms and disease course in multiple sclerosis. Genes Immun. 2003;4(4):312-315.

32. Hensiek AE, Roxburg R, Merenian M, et al. Ostepontin gene and clinical severity of multiple sclerosis. J Neurol. 2003;250(8):943-947.

33. Braitch M, Nunan R, Niepel G, Edwards LJ, Constantinescu CS. Increased osteopontin levels in the cerebrospinal fluid of patients with multiple sclerosis. Arch Neurol. 2008;65(5):633-635.

34. Chabas D, Baranzini SE, Mitchell D, et al. The influence of the proinflammatory cytokine, Osteopontin, on autoimmune demyelinating disease. Science. 2001; 294(5547):1731-1735.

35. Bornsen L, Khademi M, Olsson T, Sørensen PS, Finn Sellebjerg F. Osteopontin concentrations are increased in cerebrospinal fluid during attacks of multiple sclerosis. Mult Scler. 2011;17(1):32-42.

36. Khademi M, Bornsen L, Rafatnia F, et al. The effects of natalizumab on inflammatory mediators in multiple sclerosis: prospects for treatment-sensitive biomarkers. Eur J Neurol. 2009;16(4):528-536.

37. Romme Christensen J, Börnsen L, Khademi M, et al. CSF inflammation and axonal damage are increased and correlate in progressive multiple sclerosis. Mult Scler. 2013; 19(7):877-884.

38. Denhardt DT, Noda M, O’Regan AW, Pavlin D, Berman JS. Osteopontin as a means to cope with environmental insults: regulation of inflammation, tissue remodeling, and cell survival. J Clin Invest. 2001;107(9):1055-1061.

39. Del Prete A, Scutera S, Sozzani S, Musso T. Role of Osteopontin in dendritic cell shaping of immune responses. Cytokine Growth Factor Rev. 2019;50:19-28.

40. Hur EM, Youssef S, Haws ME, Zhang SY, Sobel RA, Steinman L. Osteopontininduced relapse and progression of autoimmune brain disease through enhanced survival of activated T cells. Nat Immunol. 2007;8(1):74-83.

41. Machado-Santos J, Saji E, Tröscher AR, et al. The compartmentalized inflammatory response in the multiple sclerosis brain is composed of tissue-resident CD8+ T lymphocytes and B cells. Brain. 2018;141(7):2066-2082.

42. Magliozzi R, Howell OW, Reeves CA, et al. A Gradient of neuronal loss and meningeal inflammation in multiple sclerosis. Ann Neurol. 2010;68(4):477-493.

43. Reynolds R, Roncaroli F, Nicholas R, Radotra B, Gveric D, Howell O. The neuropathological basis of clinical progression in multiple sclerosis. Acta Neuropathol. 2011; 122(2): 155-170.

44. Frischer JM, Bramow S, Dal Bianco A, et al. The relation between inflammation and neurodegeneration in multiple sclerosis brains. Brain. 2009;132(pt 5): 1175-1189. 


\section{Neurology \\ Neuroimmunology \& Neuroinflammation}

\section{CSF Levels of CXCL12 and Osteopontin as Early Markers of Primary Progressive Multiple Sclerosis \\ Damiano Marastoni, Roberta Magliozzi, Anna Bolzan, et al. \\ Neurol Neuroimmunol Neuroinflamm 2021;8; \\ DOI 10.1212/NXI.0000000000001083}

This information is current as of September 29, 2021

\section{Updated Information \& \\ Services}

References

Citations

Subspecialty Collections

Permissions \& Licensing

Reprints including high resolution figures, can be found at: http://nn.neurology.org/content/8/6/e1083.full.html

This article cites 43 articles, 1 of which you can access for free at: http://nn.neurology.org/content/8/6/e1083.full.html\#\#ref-list-1

This article has been cited by 1 HighWire-hosted articles: http://nn.neurology.org/content/8/6/e1083.full.html\#\#otherarticles

This article, along with others on similar topics, appears in the following collection(s):

Multiple sclerosis

http://nn.neurology.org//cgi/collection/multiple_sclerosis

Information about reproducing this article in parts (figures,tables) or in its entirety can be found online at:

http://nn.neurology.org/misc/about.xhtml\#permissions

Information about ordering reprints can be found online:

http://nn.neurology.org/misc/addir.xhtml\#reprintsus

Neurol Neuroimmunol Neuroinflamm is an official journal of the American Academy of Neurology.

Published since April 2014, it is an open-access, online-only, continuous publication journal. Copyright

Copyright $\odot 2021$ The Author(s). Published by Wolters Kluwer Health, Inc. on behalf of the American

Academy of Neurology.. All rights reserved. Online ISSN: 2332-7812.

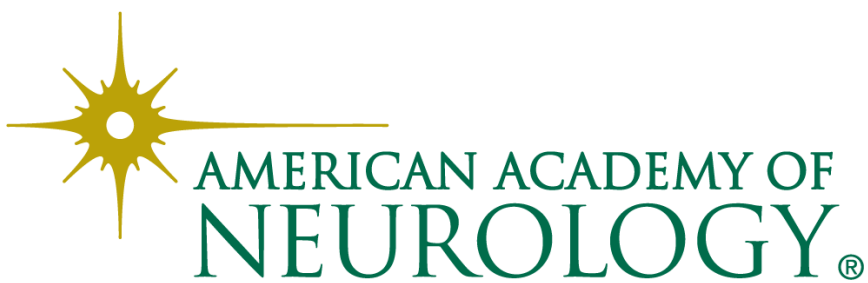

